\title{
PHYSICOCHEMICAL PROPERTIES OF DRIED GUIZHOU AS AFFECTED BY PRETREATMENTS, DRYING TECHNIQUES AND STORAGE PERIOD
}

\author{
CHANTHIMA PHUNGAMNGOEN ${ }^{1 *}$, PAKKAWAT DETCHEWA ${ }^{1}$, YARDFON TANONGKANKIT $^{2}$ \\ AND ANUCHITA MOONGNGRAM ${ }^{3}$
}

${ }^{1}$ Faculty of Agro-Industry 129, King Mongkut's University of Technology North Bangkok, Moo 21, Tambon Noenhom, Amphoe Mueang,, Prachinburi 25230 Thailand. ${ }^{2}$ Maejo University Faculty of Engineering and Agro-Industry Nong Han, Chiang Mai, Thailand. ${ }^{3}$ Food Technology and Nutrition, Mahasarakham University, Moo 20 Khamriang Kantarawichai, KantHarawichai, Maha Sarakham 44150 Thailand.

*Corresponding author: chanthima.p@agro.kmutnb.ac.th

Submitted final draft: 7 January 2021 Accepted: 26 January 2021

http://doi.org/10.46754/jssm.2021.07.001

\begin{abstract}
The effects of pretreatment methods (hot-water blanching, steam blanching and acetic acid soaking) and drying techniques (hot-air drying, vacuum drying and freeze drying) on the physical properties and antioxidant activities of dried Guizhou are investigated in this study. Results show that blanching improved the drying rate, and was faster than untreated and acetic acid treated samples. Vacuum drying resulted in slower drying than hot air. Samples subject to hot-air drying and vacuum drying exhibited more shrinkage than those subjected to freeze drying. Dried-blanched samples had greener and darker color than acetic acid pretreated and untreated dried samples. Freeze-dried samples had the highest total phenolic compounds and antioxidant activity determined by DPPH assay. Moisture content, water activity, color change $(\Delta E)$ of hot air dried, vacuumdried and freeze-dried samples gradually increased throughout the 6-month storage period, while total phenolic compounds and DPPH radical scavenging activity showed a decreasing trend. Aluminum foil provided better protection against moisture uptake by dried samples than polypropylene containers. Freeze-dried samples kept in aluminum foil at room temperature gave the longest shelf life. Results suggested that pretreatment by blanching, suitable drying methods and aluminum packaging improved physical properties and protected phenolic acid content of dried Guizhou.
\end{abstract}

Keywords: Pretreatment, Guizhou, drying method, antioxidant, shelf life.

\section{Introduction}

Guizhou (Artemisia lactiflora) is known as mugwort or Jing-ju-chai in Thailand. The leaves are used as a traditional Chinese medicine to treat menstrual disorders and also have anti-cancer and anti-oxidative properties. Kulprachakarn et al. (2018) reported antioxidant activity of Guizhou at $27.20 \pm 1.06 \mathrm{mg} \mathrm{TEAC} / \mathrm{g}$ of dry extract, with total phenolic content of $213.33 \pm 117.80 \mathrm{mg}$ GAE/g of dry extract. However, utilization of fresh Guizhou is restricted because it is a perishable plant. Drying is therefore proposed to extend its storage life.

Drying is a popular post harvest process to reduce water content. Reduction of water y $\left(a_{\mathrm{w}}\right)$ to a low level, whereby growth of microorganisms, enzymatic, and other deteriorative reactions are inhibited, prolongs the shelf life of the products.
Many studies reported significant color changes caused by the browning reaction (Yanyang et al., 2004; Arabhosseini et al., 2007. Different drying methods operate under diverse conditions. For example, in vacuum drying and freeze drying, the drying chamber operates at reduced pressure as an oxygen deficient environment. Quality of vacuum dried and freeze dried products tends to be better than those subjected to conventional hot-air drying.

Normally, pretreatment is applied before drying to reduce contamination by microorganisms (Phungamngoen et al., 2013) and improve the physicochemical properties of the product (Farooq et al., 2020). There are many methods for pretreating fruits and vegetables. Chiewchan \& Morakotjinda (2009) reported that soaking sliced cabbage in acetic acid (0.5- 
$1.5 \% \mathrm{v} / \mathrm{v})$ reduced the number of Salmonella anatum on the cabbage surface. Hot water and steam treatment are widely used to improve product color (Phungamngoen et al., 2013). Hot water and steam are the simplest methods of heat treatment, with fast energy transfer as latent heat to bacterial and fungal spores on the surface of fruits and vegetables.

Many papers have been published concerning the anti-oxidant and medical properties of Guizhou but information detailing the combined effects of pretreatment and drying methods on the quality of dried Guizhou is lacking. Thus, here, the effects of pretreatment and drying techniques on physicochemical properties of dried Guizhou were investigated. Different packaging during storage on physicochemical properties of the dried product was also assessed.

\section{Materials and Methods}

\section{Pretreatments}

Fresh Guizhou was purchased from an organic farmer in Prachinburi, Thailand. The edible leaves of Guizhou were washed with tap water for 2 minutes. Guizhou leaves were pretreated by three methods, including soaking in acid, blanching and steaming.

Acid pretreatment involves soaking the samples in acetic acid solution at $0.5 \% \mathrm{v} / \mathrm{v}$ (glacial acetic acid, J.T. Baker, Phillipsburgh, USA). The Guizhou leaves to acid solution ratio was 1:10 (w/v). The mixture was shaken in a rotary shaker at $120 \mathrm{rpm}$ for 5 minutes and at $30^{\circ} \mathrm{C}$.

The blanching conditions were predetermined to inhibit peroxidase. For hot water blanching pretreatment, the sample to boiling water ratio was $1: 10$. The samples were blanched in boiling water for 4 minutes during which the enzyme peroxidase activity was not detected. Steam blanching pretreatment was followed by a water bath (Memmert, Model WNB22, Germany). A single layer of the Guizhou leaves sample was steamed by placing it on a perforated tray suspended over hot water at $97{ }^{\circ} \mathrm{C}$ for 2 minutes. After blanching the samples were immediately cooled in a water bath at $4-5^{\circ} \mathrm{C}$. Fresh Guizhou leaves were used as control.

\section{Drying Methods}

Approximately $300 \mathrm{~g}$ of pretreated samples were placed on a $50 \times 70 \mathrm{~cm}$ tray and spread in a single layer. Samples were dried at $60^{\circ} \mathrm{C}$ with an average air flow velocity of $1.6 \mathrm{~m} / \mathrm{s}$ in a hot air dryer (Kluaynamthai, 12Tray, Thailand). Samples were taken at regular intervals to measure moisture content using a standard gravimetric method (AOAC, 2000). Drying time required to obtain the products with the final moisture content of less than $8 \%$ (w.b.).

Vacuum drying was conducted following the same procedure using different equipment (Memmert, Model VO500, Germany). All experiments were performed under pressure of 10 mbar, with drying temperatures at $60^{\circ} \mathrm{C}$. Freeze drying was conducted under pressure of $70 \mathrm{~Pa}$ for 24 hours. Before drying, the samples were frozen at $-40^{\circ} \mathrm{C}$ for 20 hours and then dried using a ScanVac Model CoolSafe 4-15L, Germany. All experiments were performed in triplicate.

\section{Storage Period}

To evaluate the physicochemical properties, $10 \mathrm{~g}$ of dried samples were kept at room temperature $\left(\sim 30^{\circ} \mathrm{C}\right)$ for 6 months with two types of packaging - aluminum foil and polypropylene containers.

\section{Water Activity Determination}

$3-5 \mathrm{~g}$ of dried samples were placed in quartz cuvette and water activity $\left(a_{\mathrm{w}}\right)$ was measured using a Water Activity Meter (AquaLab Model Series 3TE, Washington, USA) at $25^{\circ} \mathrm{C}$ after calibration with saturated salt solutions ranging between 0.33 and 0.85 .

\section{Color Measurement}

The samples were placed in cuvette and then placed in a Hunter Colorimeter (Hunter Lab, Model Colorflex 45/0, Virginia). Reflection 
spectra were registered and Hunter Lab color parameters for $10^{\circ}$ vision angle and D65 illuminant ( $L$ : brightness, $a$ : redness, $b$ : yellowness) were calculated. The color of dried samples were compared with the color value of fresh Guizhou leaves. Total color change $(\Delta E)$ was also calculated as:

$\Delta E=\sqrt{(\Delta L)^{2}+(\Delta a)^{2}+(\Delta b)^{2}}$

$\Delta L=L-L_{0}, \Delta a=a-a_{0}$ and $\Delta b=b-b_{0}$

where $L_{0}, a_{0}, b_{0}$ are the color values of fresh Guizhou leaves.

\section{Total Phenolic Content}

Guizhou tea was prepared for measuring the total phenolic content (TPC). Dried samples (2g) were steeped in $200 \mathrm{~mL}$ hot water (approximately $97^{\circ} \mathrm{C}$ ) for $5 \mathrm{~min}$. Total phenolic content of dried Guizhou extracts was determined by the FolinCiocalteu method, performed following the method of Johari \& Khong (2019). Briefly, $100 \mu \mathrm{L}$ of the extract $(1 \mathrm{mg} / \mathrm{mL})$ was mixed thoroughly with $0.75 \mathrm{~mL}$ of Folin-Ciocalteu reagent for 5 minutes, followed by adding of $0.75 \mathrm{~mL}$ of sodium carbonate $\left(\mathrm{Na}_{2} \mathrm{CO}_{3}\right)$. The test tube was kept in the dark for 30 minutes. The absorbance of the mixture was measured using a UV-Vis Spectrophotometer (Biochrom, Model Libra s12, USA) at $750 \mathrm{~nm}$. The total phenolic content was calculated from the calibration curve, and the results were expressed as $\mathrm{mg}$ of gallic acid equivalent per $\mathrm{g}$ dry weight (mg $\mathrm{GAE} / \mathrm{g})$.

\section{DPPH Radical Scavenging Assay}

The antioxidant activity of the extract was determined by the 1,1-diphenyl-2-picrylhydrazyl (DPPH) assay as previously described by Johari \& Khong (2019) with some modifications. About $0.1 \mathrm{mM}$ solution of DPPH in ethanol was prepared and $1 \mathrm{~mL}$ of DPPH solution was added to $3 \mathrm{~mL}$ of the sample with different concentrations. The mixture was shaken and kept in the dark for 30 minutes at room temperature. Then, the absorbance was measured at $517 \mathrm{~nm}$ using the UV-Vis spectrophotometer. The calculation for the percentage of inhibition of the DPPH radical is:

$\%$ inhibition $=\frac{\left(A_{0}-A_{s}\right)}{A_{0}} \times 100 \%$

where $A_{0}$ represents absorbance value of the control reaction (contains all reagents except the sample), and $A_{\mathrm{S}}$ represents absorbance value of the sample.

\section{Experimental Design and Statistical Analysis}

The first part of the experiments were conducted at three levels of the pretreatment methods (acetic acid soaking, hot water blanching and steam blanching) and three levels of the drying methods (hot air drying, vacuum drying and freeze drying). The second part was conducted at two levels of the packaging (aluminum foil and polypropylene). A completely randomized design (CRD) was used to schedule the experiments. Differences between mean values were established using Tukey's multiple range tests at a confidence level of $95 \%$.

\section{Results and Discussion}

\section{Effect of Pretreatments}

Table 1 shows the effect of pretreatments on moisture content and water activity of the samples. Pretreated samples showed no significant difference in water activity (0.9790.994). Initial moisture content of the untreated sample was $17.26 \pm 1.01 \mathrm{~g} / \mathrm{g}$ (dry basis). Water blanching and steam blanching pretreatment led to higher moisture content than soaking in $0.5 \%$ acetic acid pretreatment and the untreated sample because disruption of plant cells allowed the uptake of cool water after blanching (Gonzalez-Fesler, 2008), consistent with the findings of Phungamngoen et al. (2013).

\section{Combined Effect of Pretreatments and Drying Methods}

Effects of pretreatment and drying methods on drying time, moisture content and water activity $\left(a_{\mathrm{w}}\right)$ of dried Guizhou are presented in Table 2. Hot air drying and vacuum drying 
Table 1: Moisture content and water activity $\left(a_{\mathrm{w}}\right)$ of pretreated dried Guizhou.

\begin{tabular}{lcc}
\hline \multicolumn{1}{c}{ Pretreatment } & $\begin{array}{c}\text { Moisture content } \\
\text { (g/g dry basis) }\end{array}$ & $\boldsymbol{a}_{\boldsymbol{w}}$ \\
\hline Untreated & $17.26 \pm 1.01^{\mathrm{b}}$ & $0.979 \pm 0.006^{\mathrm{b}}$ \\
Water blanching & $20.07 \pm 2.41^{\mathrm{abc}}$ & $0.994 \pm 0.001^{\mathrm{a}}$ \\
Steam blanching & $19.74 \pm 0.67^{\mathrm{a}}$ & $0.990 \pm 0.003^{\mathrm{a}}$ \\
Acid pretreatment & $17.65 \pm 2.77^{\mathrm{ab}}$ & $0.990 \pm 0.004^{\mathrm{a}}$ \\
\hline
\end{tabular}

Mean values in the same column with different superscripts are significantly different $(\mathrm{P}<0.05)$.

Table 2: Drying time, moisture content and water activity $\left(a_{\mathrm{w}}\right)$ of dried Guizhou with different pretreatments and drying methods.

\begin{tabular}{lcccc}
\hline \multicolumn{1}{c}{ Pretreatment } & Drying method & Drying time (h) & $\begin{array}{c}\text { Moisture } \\
\text { content } \\
\text { (\%od.b.) }\end{array}$ & $\boldsymbol{a}_{w}$ \\
\hline Untreated & & $2.40 \pm 0.08^{\mathrm{c}}$ & $8.04 \pm 0.01^{\mathrm{a}}$ & $0.429 \pm 0.010^{\mathrm{a}}$ \\
Water blanching & Hot air drying & $2.00 \pm 0.08^{\mathrm{d}}$ & $7.93 \pm 0.03^{\mathrm{a}}$ & $0.268 \pm 0.001^{\mathrm{e}}$ \\
Steam blanching & $2.05 \pm 0.20^{\mathrm{d}}$ & $7.92 \pm 0.20^{\mathrm{a}}$ & $0.301 \pm 0.003^{\mathrm{d}}$ \\
Acid pretreatment & & $2.55 \pm 0.05^{\mathrm{c}}$ & $7.71 \pm 0.21^{\mathrm{ab}}$ & $0.301 \pm 0.003^{\mathrm{d}}$ \\
\hline Untreated & & $8.20 \pm 0.16^{\mathrm{a}}$ & $8.01 \pm 0.01^{\mathrm{a}}$ & $0.395 \pm 0.009^{\mathrm{b}}$ \\
Water blanching & & $7.20 \pm 0.08^{\mathrm{b}}$ & $7.96 \pm 0.04^{\mathrm{a}}$ & $0.399 \pm 0.011^{\mathrm{ab}}$ \\
Steam blanching & Vacuum drying & $7.00 \pm 0.08^{\mathrm{b}}$ & $7.80 \pm 0.14^{\mathrm{a}}$ & $0.369 \pm 0.005^{\mathrm{c}}$ \\
Acid pretreatment & & $7.90 \pm 0.08^{\mathrm{a}}$ & $7.94 \pm 0.02^{\mathrm{a}}$ & $0.423 \pm 0.004^{\mathrm{a}}$ \\
\hline Untreated & & & $7.16 \pm 0.11^{\mathrm{c}}$ & $0.320 \pm 0.060^{\mathrm{cd}}$ \\
Water blanching & & & $7.02 \pm 0.07^{\mathrm{c}}$ & $0.280 \pm 0.017^{\mathrm{de}}$ \\
Steam blanching & Freeze drying & Overnight & $7.03 \pm 0.06^{\mathrm{c}}$ & $0.267 \pm 0.015^{\mathrm{e}}$ \\
Acid pretreatment & & & $7.14 \pm 0.23^{\mathrm{c}}$ & $0.307 \pm 0.021^{\mathrm{de}}$ \\
\hline
\end{tabular}

Mean values in the same column with different superscripts are significantly different $(\mathrm{P}<0.05)$.

exhibited similar behavior for all samples (data not shown). Moisture content decreased continuously as drying time increased. Drying time of the vacuum-dried sample was longer than the hot-air dried sample since velocity flow in the hot-air dryer was approximately 2 $\mathrm{m} / \mathrm{s}$, while there was no air movement in the vacuum dryer with low mass transfer rate. In the case of freeze drying, the sample was pre frozen overnight before the drying process.

Results showed that blanched samples dried faster than unblanched samples due to structure softening during blanching that accelerated water removal. When plant tissues are blanched or cooked, the cells become more permeable to moisture. Similar observations were reported for drying vegetable leaves (Lopez et al., 2000; Phungamngoen et al., 2013). Final moisture content and $a_{\mathrm{w}}$ of freeze dried samples were lower than hot-air dried and vacuum-dried samples. According to the Thai Community Product Standard No. 120 (2016), green tea should have a moisture content at less than $8 \%$. Results showed that moisture content of the dried products were all below this standard, with $a_{\mathrm{w}}$ values ranging 0.267 to 0.429 .

Dried samples obtained from the different pretreatments using hot-air drying at $60^{\circ} \mathrm{C}$ are shown in Figure 1. Blanched leaves exhibited more shrinkage than acid pretreated and untreated samples because thermal processing inhibited the enzymatic browning reaction 


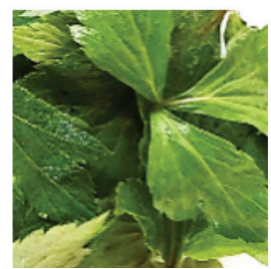

(a)

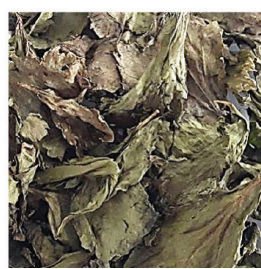

(b)

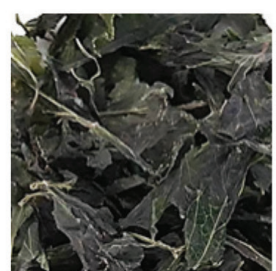

(c)

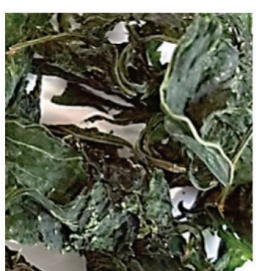

(d)

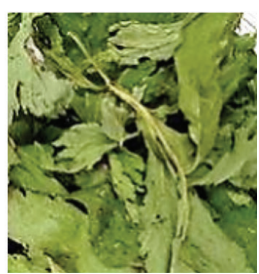

(e)

Figure 1: Dried Guizhou with different pretreatments, (a) fresh Guizhou, (b) untreated, (c) water blanching, (d) steam blanching, and (e) soaking in $0.5 \%$ acetic acid using hot air drying at $60{ }^{\circ} \mathrm{C}$.

and reduced the drying time due to tissue wall softening (Oboh, 2005). The hot water and steam blanched products showed greater shrinkage. However, the applied pretreatment combined with drying methods did not show effect on the shrinkage of the dried Guizhou.

Table 3 shows the color values of dried samples at final moisture content. Untreated samples had a redder color than acid pretreated and blanched samples, respectively. This was due to enzymatic browning reactions that were activated during the drying process for nonthermal treatment methods, as shown in the case of untreated and acid pretreated samples. Blanched samples became darker and greener with slight loss of yellowness due to leaching of the soluble pigments during blanching
(Wolfe \& Liu, 2003), while blanching inhibited enzymatic browning reactions leading to less red color. In addition, blanching pretreatment led to intercellular air trapped in the vegetable could obstruct the greenness of chlorophyll (Phungamngoen et al., 2013). Although vacuum drying and freeze drying took longer than hot-air drying, the lightness ( $L$ value) of vacuum-dried and freeze-dried samples showed a higher value than the hot-air dried sample. This occurred because the drying chambers of vacuum drying and freeze drying are operated at reduced pressure or vacuum in an oxygen-deficient environment. Removal of the air in the chamber during drying resulted in the strong green color of the dried Guizhou. The final moisture content of blanched samples exhibited higher total color change $(\Delta E)$ than acid pretreated samples.

Table 3: Effect of pretreatments and drying methods on color properties of dried Guizhou.

\begin{tabular}{lccccc}
\hline \multicolumn{1}{c}{ Pretreatment } & $\begin{array}{c}\text { Drying } \\
\text { method }\end{array}$ & $\boldsymbol{L}$ & $\boldsymbol{a}$ & $\boldsymbol{b}$ & $\begin{array}{c}\text { Total color change } \\
(\boldsymbol{\Delta} \boldsymbol{E})\end{array}$ \\
\hline Untreated & & $35.72 \pm 1.78^{\mathrm{cd}}$ & $-0.37 \pm 0.80^{\mathrm{b}}$ & $12.81 \pm 0.68^{\mathrm{a}}$ & $85.07 \pm 9.75^{\mathrm{d}}$ \\
Water blanching & Hot air & $28.80 \pm 1.23^{\mathrm{e}}$ & $-3.95 \pm 0.24^{\mathrm{c}}$ & $8.77 \pm 0.88^{\mathrm{bc}}$ & $116.35 \pm 18.32^{\mathrm{ab}}$ \\
Steam blanching & drying & $28.69 \pm 0.60^{\mathrm{e}}$ & $-3.74 \pm 0.25^{\mathrm{c}}$ & $8.52 \pm 1.55^{\mathrm{bcd}}$ & $114.01 \pm 36.24^{\mathrm{abcd}}$ \\
Acid pretreatment & & $34.26 \pm 1.58^{\mathrm{d}}$ & $-0.03 \pm 0.20^{\mathrm{a}}$ & $12.06 \pm 0.35^{\mathrm{a}}$ & $99.54 \pm 3.35^{\mathrm{bc}}$ \\
\hline Untreated & & $41.08 \pm 0.48^{\mathrm{b}}$ & $-3.29 \pm 0.43^{\mathrm{c}}$ & $8.03 \pm 0.71^{\mathrm{d}}$ & $95.72 \pm 0.70^{\mathrm{c}}$ \\
Water blanching & Vacuum & $29.44 \pm 0.97^{\mathrm{e}}$ & $-4.61 \pm 0.32^{\mathrm{d}}$ & $8.47 \pm 1.12^{\mathrm{bcd}}$ & $117.62 \pm 23.54^{\mathrm{ab}}$ \\
Steam blanching & drying & $28.51 \pm 1.91^{\mathrm{e}}$ & $-4.28 \pm 0.31^{\mathrm{cd}}$ & $8.45 \pm 1.29^{\mathrm{bcd}}$ & $118.81 \pm 25.23^{\mathrm{ab}}$ \\
Acid pretreatment & & $44.10 \pm 0.67^{\mathrm{a}}$ & $-3.83 \pm 0.13^{\mathrm{c}}$ & $8.49 \pm 0.33^{\mathrm{b}}$ & $102.35 \pm 0.57^{\mathrm{b}}$ \\
\hline Untreated & & $38.76 \pm 0.63^{\mathrm{bc}}$ & $-3.51 \pm 0.11^{\mathrm{c}}$ & $8.08 \pm 0.44^{\mathrm{cd}}$ & $30.04 \pm 6.70^{\mathrm{f}}$ \\
Water blanching & Freeze & $33.76 \pm 0.58^{\mathrm{d}}$ & $-4.43 \pm 1.85^{\mathrm{d}}$ & $7.88 \pm 0.42^{\mathrm{d}}$ & $30.34 \pm 0.82^{\mathrm{f}}$ \\
Steam blanching & drying & $34.63 \pm 0.85^{\mathrm{d}}$ & $-3.92 \pm 0.31^{\mathrm{cd}}$ & $7.16 \pm 0.88^{\mathrm{e}}$ & $30.08 \pm 3.41^{\mathrm{ef}}$ \\
Acid pretreatment & & $38.72 \pm 1.42^{\mathrm{bc}}$ & $-4.07 \pm 0.47^{\mathrm{cd}}$ & $8.92 \pm 0.75^{\mathrm{b}}$ & $30.38 \pm 14.75^{\mathrm{ef}}$ \\
\hline
\end{tabular}

Mean values in the same column with different superscripts are significantly different $(\mathrm{P}<0.05)$. 
This is probably because the removal of air in the drying chamber could preserve chlorophyll pigment, the $\Delta E$ of blanched samples was larger than the acid pretreated sample. However, hot water and steam blanching had little effect on the $\Delta E$ of dried Guizhou.

Total phenolic content and DPPH radical scavenging activity of dried Guizhou are indicated in Table 4. Results showed that steam blanching had higher TPC and DPPH than water blanching, soaking in $0.5 \%$ acetic acid and the untreated sample. Although blanching applied high heat to the sample, it reduced drying time to reach final moisture content and prevented quality loss during drying. High TPC gave high percentage inhibition of DPPH due to the linear correlation between the two parameters. Freeze drying under lower pressure then removing the ice by sublimation, is used to prolong the shelf life of samples. Freeze drying causes less damage to substances than other drying methods using higher temperature and retains antioxidant activity of the product. These results concurred with Farooq et al. (2020). Based on quality with high antioxidant activity of dried Guizhou, steam blanching using hot air drying, vacuum drying and freeze drying were selected as the three conditions to study the effect of packaging during storage because they gave the highest TPC of each drying method.

\section{Effect of Different Packaging during Storage}

Figure 2 shows moisture content (A), water activity (B) and total color change (C) of dried Guizhou during storage. Moisture content of tea stored in aluminum foil and polypropylene (PP) increased as storage time went on. The changes in moisture content of dried Guizhou are caused by the relative humidity of the environment. When the relative humidity of the air was higher than the product, then the material could absorb water.

Aluminum foil and PP packaging showed no difference in moisture content during storage for 6 months. This is because the packaging is able to maintain water vapour within and outside the product, resulting in no water vapour transfer during storage. Results indicated that increasing moisture content was confirmed by the change of $a_{\mathrm{w}}$ during storage (Figure 1B).

In all cases, TPC and DPPH decreased with increasing storage period. For vacuum drying and freeze drying (Figure 3), the destruction of antioxidant parameters was more pronounced during the first period of storage due to a sudden

Table 4: Effect of pretreatments and drying methods on total phenolic content and DPPH of dried Guizhou.

\begin{tabular}{lccc}
\hline \multicolumn{1}{c}{ Pretreatment } & Drying method & $\begin{array}{c}\text { Total phenolic content } \\
\text { (mg GAE/g) }\end{array}$ & $\begin{array}{c}\text { DPPH } \\
\text { (\% inhibition) }\end{array}$ \\
\hline Untreated & $184.61 \pm 14.89^{\mathrm{j}}$ & $23.93 \pm 0.29^{\mathrm{f}}$ \\
Water blanching & Hot air drying & $567.51 \pm 18.90^{\mathrm{f}}$ & $26.73 \pm 0.42^{\mathrm{e}}$ \\
Steam blanching & $593.43 \pm 18.47^{\mathrm{ef}}$ & $27.69 \pm 0.55^{\mathrm{e}}$ \\
Acid pretreatment & & $494.34 \pm 25.72^{\mathrm{i}}$ & $25.37 \pm 0.24^{\mathrm{e}}$ \\
\hline Untreated & & $496.22 \pm 26.80^{\mathrm{i}}$ & $26.34 \pm 0.72^{\mathrm{e}}$ \\
Water blanching & \multirow{2}{*}{ Vacuum drying } & $638.73 \pm 17.32^{\mathrm{e}}$ & $28.08 \pm 1.08^{\mathrm{e}}$ \\
Steam blanching & & $858.11 \pm 33.47^{\mathrm{b}}$ & $28.31 \pm 4.28^{\mathrm{d}}$ \\
Acid pretreatment & & $542.06 \pm 14.07^{\mathrm{gh}}$ & $26.49 \pm 1.09^{\mathrm{ed}}$ \\
\hline Untreated & & $834.19 \pm 71.89^{\mathrm{b}}$ & $31.51 \pm 5.26^{\mathrm{d}}$ \\
Water blanching & & $784.61 \pm 44.89^{\mathrm{c}}$ & $53.83 \pm 4.88^{\mathrm{ab}}$ \\
Steam blanching & \multirow{2}{*}{ Freeze drying } & $946.27 \pm 12.63^{\mathrm{a}}$ & $63.86 \pm 10.66^{\mathrm{a}}$ \\
Acid pretreatment & & $716.13 \pm 19.54^{\mathrm{d}}$ & $43.98 \pm 0.29^{\mathrm{c}}$ \\
\hline
\end{tabular}

Mean values in the same column with different superscripts are significantly different $(\mathrm{P}<0.05)$. 

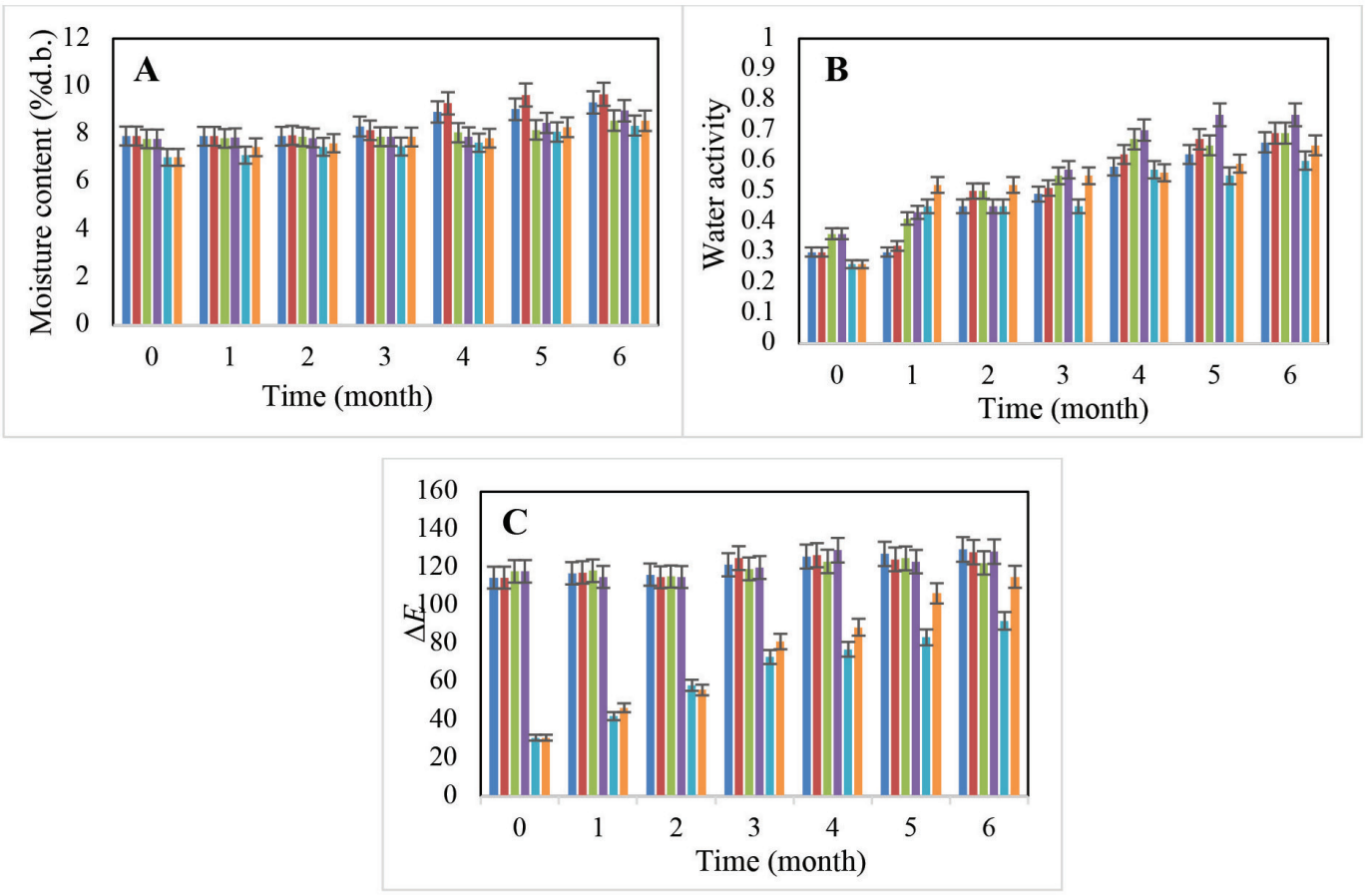

Figure 2: Physiochemical properties change of dried Guizhou during storage by hot air drying kept in foil ( $\square$ ) and polypropylene ( $\square$ ); vacuum drying kept in foil $(\square)$ and polypropylene ( $\square$ ) and freeze drying

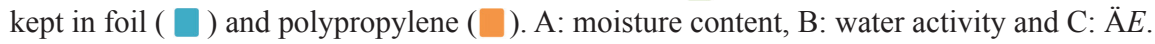
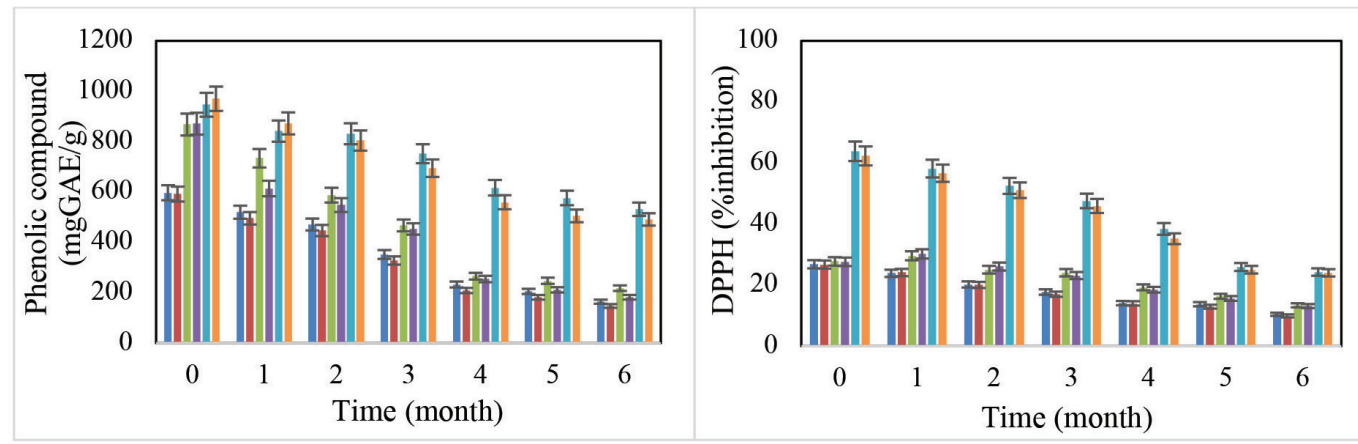

Figure 3: Change in phenolic compounds and antioxidant activity by DPPH radical scavenging assay of dried Guizhou during storage by hot air drying kept in foil ( $\square$ ) and polypropylene ( $\square$ ), vacuum drying kept in foil ( $\square$ ) and polypropylene ( $\square$ ), and freeze drying kept in foil ( $\square$ ) and polypropylene ( $\square$ ).

decrease in the value of TPC and DPPH. At the initial period of storage, DPPH was highest in freeze-dried samples followed by vacuum dried and hot-air dried samples. There was only a slight reduction in DPPH of hot air dried and vacuum dried samples during storage compared to initial values. Freeze dried samples showed a significant reduction in DPPH compared to other drying methods.
The effect of packaging was more pronounced for the change of DPPH during storage in the case of freeze dried samples. Aluminum foil retained DPPH and TPC better than PP packaging. Products stored in aluminum foil were of better quality than those stored in PP packaging. 


\section{Shelf Life}

Moisture content is essential to determine shelf life of dried products. Changes in moisture content of dried products under different conditions of storage are presented in Figure 4. Moisture content increased with increasing storage time for all conditions. Changes in moisture content fitted to a first order regression model with good correlation $\left(R^{2}=0.6848\right.$ 0.9538 ). Results in Table 5 showed that freezedried products showed the highest correlation (0.9456-0.9538) followed by hot-air dried products $(0.8506-0.9042)$ and vacuum-dried products (0.6848-0.6903), respectively. Based on the standard moisture content of tea at less than $8 \%$ (Thai Community Product Standard No. 120, 2016), longer shelf life was observed in products packed in aluminum foil bags compared to products packed in polypropylene bags. The layer of aluminum foil was found to be good for long-term storage of dried product; this observation was consistent with Gogoi et al. (2006).

\section{Conclusions}

How the physicochemical properties of dried Guizhou are affected by pretreatment, drying method and storage period were investigated.
Treatment of Guizhou with $0.5 \%$ acetic acid did not affect drying time by hot-air drying and vacuum drying but resulted in a significant increase in total color change, TPC and DPPH. Blanched samples exhibited shorter drying time than untreated and treated in acid samples. Blanching pretreatment with steam and hot water improved antioxidant activity (higher TPC and DPPH) of dried Guizhou. Steam blanched product for each drying method was selected to study the effect of different packaging during storage. Freeze-dried samples showed higher TPC and DPPH (\% inhibition) than vacuum dried and hot-air dried samples during the first period of storage ( 0 month). During storage for 6 months, physical properties of dried products exhibited an increasing trend, while antioxidant activity showed a decreasing trend. First order regression analysis was used to predict change in water activity of all dried products $\left(R^{2}=\right.$ $0.6848-0.9538$ ). Freeze-dried samples kept in aluminium foil at room temperature gave the longest shelf life at 4.86 months.

\section{Acknowledgements}

Authors wish to thank the reviewers and editors for the constructive comments and also to the university for the research opportunity.

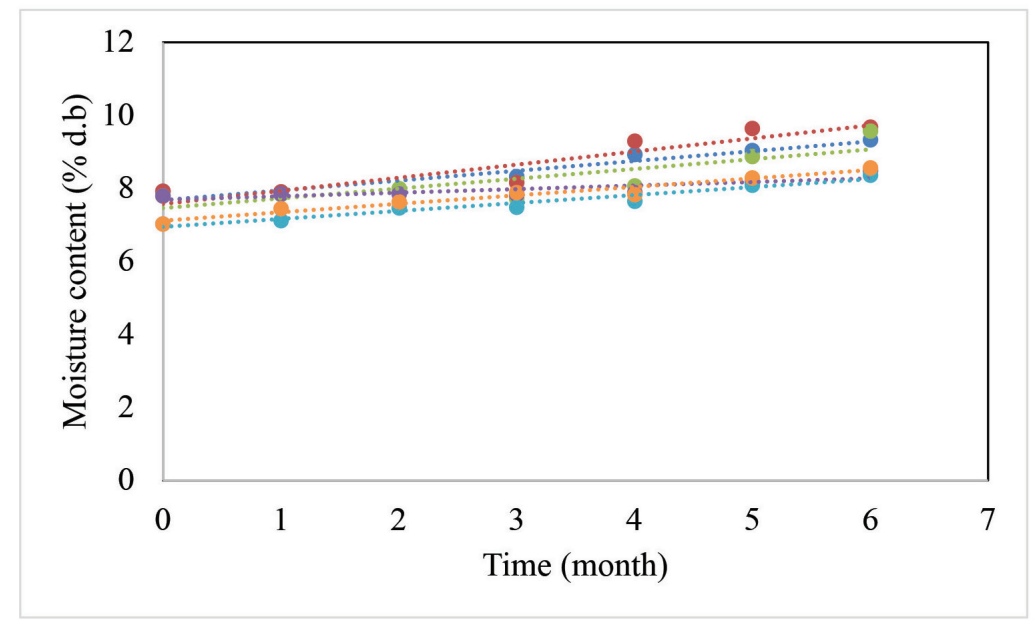

Figure 4: Moisture content change of dried Guizhou during storage by hot air drying kept in foil ( $\square$ ) and polypropylene ( $\square$ ), vacuum drying kept in foil ( $\square$ ) and polypropylene ( $\square$ ) and freeze drying kept in foil ( $\square$ ) and polypropylene ( $\square$ ). 
Table 5: Prediction model for shelf life of dried Guizhou kept in different packaging.

\begin{tabular}{ccccc}
\hline Drying method & Packaging & Model* & $\boldsymbol{R}^{2}$ & $\begin{array}{c}\text { Shelf life } \\
\text { (month) }\end{array}$ \\
\hline \multirow{2}{*}{ Hot air drying } & Aluminum foil & $y=0.2682 t+7.6754$ & 0.9042 & 1.21 \\
& Polypropylene & $y=0.3589 t+7.5718$ & 0.8506 & 1.19 \\
\hline \multirow{2}{*}{ Vacuum drying } & Aluminum foil & $y=0.2679 t+7.4593$ & 0.6903 & 2.02 \\
& Polypropylene & $y=0.1575 t+7.6861$ & 0.6848 & 1.99 \\
\hline \multirow{2}{*}{ Freeze drying } & Aluminum foil & $y=0.2170 t+6.9450$ & 0.9453 & 4.86 \\
& Polypropylene & $y=0.2314 t+7.1143$ & 0.9538 & 3.83 \\
\hline
\end{tabular}

$*_{y}=$ moisture content $(\%$ w.b. $)$ and $t=$ time (month)

\section{References}

Alagbe, E.E., Daniel, E.O. \& Oyeniyi, E.A. (2020). Dataset on effect of different pretreatment on the proximate analysis, microbial and sensory evaluation of dried banana during its storage. Data in Brief, 31, $1-5$.

Arabhosseini, A., Huisman, W., Van Boxtel, A \& Muller, J. (2007). Long-term effects of drying conditions on the essential oil and color of tarragon leaves during storage. Journal of Food Engineering, 79 (2), 561566.

Arevalo-Pinedo, A., Murr, F.E.X., GiraldoZuniga, A.D. \& Arevalo, Z.D.S. (2004). Vacuum drying of carrot (Daucus carota): effects of pretreatments and parameters process. In Proceedings of the $14^{\text {th }}$ International Drying Symposium, Sao Paulo, Brazil, 2021-2062.

Baini, B. \& Langrish, T.A.G. (2009). Assessment of colour development in dried bananas measurements and implications for modeling. Journal of Food Engineering, 93, 177-182.

Chiewchan, N \& Morakotjinda, P. (2009). Effects of acetic acid pretreatment and hot air drying on resistance of Salmonella on cabbage slices. Drying Technology, 27, 955-
961.

Farooq, S., Rather, S.A., Gull, A., Ganai, S.A., Masoodi, F.A., Wani, S.M. \& Ganaie, T.A. (2020). Physicochemical and nutraceutical properties of tomato powder as affected pretreatments, drying methods, and storage period. International Journal of Food Properties, 23(1), 797-808.

Gogoi, R.C., Das, D., Hazarika, D.J., Baruah, B.D., Tamuly, P. \& Sanyal, S. (2006). Jutebased aluminium foil laminated bag for packaging tea. Two and a Bud, 53(1\&2), 26-31.

Gonzalez-Fesler, M., Salvatori, D., Gomez, P. \& Alzamora, S.M. (2008). Convective air drying of apples as affected by blanching and calcium impregnation. Journal of Food Engineering, 87, 323-332.

Ibrahim, D. (2010). Effect of citric acid and blanching pre-treatments on drying and rehydration of Amasya red apples. Journal of Food and Bioproducts Processing, 88, 124-132.

Johari, M.A. \& Khong, H.Y. (2019). Total phenolic content and antioxidant and antibacterial activities of Pereskia bleo. Advances in Pharmacological Sciences, 2019, 1-4. 
Kulprachakarn, K., Pangjit, K., Paradee, N., Srichairatanakool, S., Perkasem, K. \& Ounjaijean, S. (2018). Antioxidant properties and Cytotoxicity of white mugwort (Artemisia lactiflora) leaf extract in human hepatocellular carcinoma cell line. Walailak Journal of Science and Technology, 16(3), 185-192.

Lopez, A., Iguaz, A., Esnoz, A. \& Virsed, P. (2000). Thin-layer drying behaviour of vegetable wastes from wholesale market. Drying Technology, 18, 995-1006.

Maxwell, I.E., Yusuf, N.O., Samuel, O. \& Ijeoma, H.U. (2015). Anti-inflammatory and antioxidant activities of the methanolic leaf extract of Cissus aralioides. Journal of Pharmacological Sciences, 3, 1-6.

Murthy, K.N.C., Jayaprakasha, G.K. \& Singh, R.P. (2002). Studies on antioxidant activity of pomegranate (Punica granatum) peel extract using in vivo models. Journal of Agricultural Food Chemistry, 50, 47914795.

Nyangena, I.O., Owino, W.O., Imathiu, S. \& Ambuko, J. (2019). Effect of pretreatments prior to drying on antioxidant properties of dried mango slices. Scientific African, 6, $1-9$.

Oboh, G. (2005). Effect of blanching on the antioxidant property of some tropical green leafy vegetables. LWT-Food Science and Technology, 38(5), 513-517

Phungamngoen, C., Chiewchan, N. \& Devahastin, S. (2013). Effects of various pretreatments and drying methods on Salmonella resistance and physical properties of cabbage. Journal of Food Engineering, 115, 237-244.

Sonkar, N., Rajoriya, D., Chetana, R. \& Murthy, K.V. (2020). Effect of cultivars, pretreatment and drying on physicochemical properties of Amla (Emblica officinalis) gratings. Journal of Food Science and Technology, 57(3), 980-992.

Tian, Y.Z.J. \& Baodong, Z. (2016). Effects of different drying methods on the product quality and volatile compounds of whole shiitake mushrooms. Journal of Food Chemistry, 196, 714-722.

Thai Community Product Standard. (2016). Tea, No. 120. Database of National Food Institute. Bangkok, Thailand. 9 pages.

Wolfe, K. \& Liu, R.H. (2003). Apple peels as a value-added food ingredient. Journal of Agricultural and Food Chemistry, 51, 7683.

Yanyang, X., Min, Z., Mujumdar, A.S., Le-qun, Z. \& Jin-cai, S. (2004). Studies on hot air and microwave vacuum drying of wild cabbage. Drying Technology, 22, 2201-2209. 